\title{
Morphometric parameters based prioritization of a Mid- Himalayan watershed using fuzzy analytic hierarchy process
}

\author{
Mallika Joshi*, Pankaj Kumar, and Purabi Sarkar \\ G. B. Pant University of Agriculture and Technology, Udham Singh Nagar, Pantnagar, Uttarakhand 263153, India
}

\begin{abstract}
Watershed prioritization has become increasingly crucial for managing natural resources, especially the watersheds. A useful decision support tool to provide appropriate weights to different morphological attributes with lineage with soil erosion is required to identify environmentally stressed areas for the watershed resources. This study examines the Western Nayar watershed delineation and further examination of the watershed's morphometric parameters. The morphometric parameters were quantified under the linear, areal, and relief heads for the watershed. The prioritization of sub-watersheds was done by the fuzzy analytic hierarchy process (FAHP). The study included nine morphometric parameters for forming a pairwise comparison matrix. The fuzzy analytic hierarchy process was employed for assigning the suitable weights to morphometric parameters, and further, these weights are normalized to assign the final ranks to the sub-watershed. In Western Nayar, SW9 got the highest priority, and SW1 was categorized as the least priority. The results were validated by the consistency ratio index, which depends on the matrix consistency index's size that should be less than $10 \%$. The consistency index of the present study was found to be $2 \%$.
\end{abstract}

\section{Introduction}

The morphological and climatic characteristics of a basin govern its hydrological response to a considerable extent. The morphological characteristics of watershed represent its measurable attributes, which are useful for synthesizing hydrological response. The importance of the morphological factors cannot be overlooked as an accurate prediction of runoff in concerned. Hence, linking the morphological parameter with the basin's hydrological characteristics can lead to a useful and straightforward procedure to simulate the hydrological behavior of the various basins, particularly the ungauged ones. Quantitative and rendition of various drainage parameters enable qualitative evaluation of surface runoff, infiltration, and susceptibility to erosion within the basin [7].

Morphometric science is the measurement, quantitation, and mathematical reckoning of the earth's surface layout, shape, and the dimension of its landforms. [8]. The analysis of morphometry of a watershed provides a quantitative description of the drainage system, which is an essential aspect for the characterization of watersheds [16]. Morphometric analysis requires measurement of linear features, areal aspects, the gradient of channel network, and contributing ground slopes of drainage basin [17]. The remote sensing technique is a convenient method for morphometric analysis. Large areas of synoptic view are easily procured through satellite imagery, and these are very useful in analyzing drainage basin morphometry. Pioneering work on the drainage basin morphometry has been carried out by Horton [10;
13], Miller [12], Strahler [16]. Some recent studies on morphometric analysis using remote sensing techniques have been carried out $[1 ; 3 ; 4 ; 5 ; 9 ; 15 ; 17]$. Geomorphological parameters such as stream order, stream length, stream frequency, drainage density, texture ratio, farm factor, circulatory ratio, elongation ratio, bifurcation ratio, and compactness ratio have been widely used for the prioritization of subwatersheds in a watershed [1].

Watersheds prioritization is the ranking of different sub-watersheds for varying levels of conservation treatments to be given to such watersheds. Once the watersheds are prioritized, the quantitative assessment of hydrological parameters of the watershed, such as peak flow and runoff volume, serves as necessary information for adopting suitable soil and water conservation measures in the watershed. The basin lies land use/land cover's physical characteristics influence these hydrologic parameters broadly, which are dynamic. The latest advances in remote sensing technology have provided handy tools for surveying, identifying, classifying forms of earth resources.

GIS-based multi-criteria decision analysis (GISMCDA) is a process of decision making in which geographical data and value judgments are brought together to obtain more information for the decisionmakers $[15 ; 17]$. The fuzzy analytic hierarchy process (AHP) has proved to be an advantageous method in multiple criteria decision-making in fuzzy and has found various applications in recent years. Its applications use a crisp point estimate method, which includes fuzzy preference programming (FPP) based nonlinear method

\footnotetext{
$\overline{\text { * Corresponding author: pankaj591@gmail.com }}$
} 
for fuzzy AHP priority derivation. The present study attempted to study different morphometric characteristics and implement GIS techniques through Fuzzy analytical hierarchy process (FAHP) techniques to identify critical sub-watershed in the Nayar River watershed. The morphological parameters were ranked according to the value and weights, which is evaluated by deriving the relationship between morphological parameters obtained by classification of all the sub-watershed by associating the strength of fuzzy. FHAP approach for identifying sensitive zones is found useful for implementing land and water resource conservation practices for sustainable development [2;18].

This study explores the application of fuzzy AHP approach to prioritize the Western Nayar watershed subwatersheds situated in the fragile Mid-Himalayan ecosystem using open source GIS tools and remote sensed DEM data. The results were validated by the consistency ratio index for a matrix of nine morphometric parameters.

\section{Materials and Methods}

\subsection{Study area and data procurement}

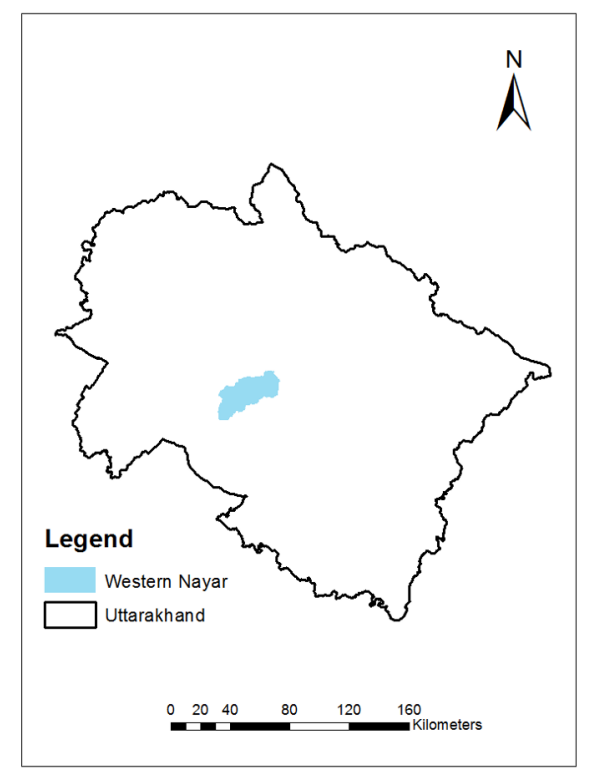

Fig. 1. Location map of study area.

The analysis has been practiced in the Western tributary of Nayar River, a non-glacial river in the Uttarakhand state of India. Nayar East and Nayar West are the two tributaries of the Nayar river. The Western Nayar lies between 29054'40''N-30012'80''N latitude and 78043'40' 'E-7909'0', E (Fig. 1). The source comprises Nayar East, which is at an elevation of $2900 \mathrm{~m}$, and the second source, which is Nayar West, has an elevation of $2800 \mathrm{~m}$. Eastern Nayar's length is about $94 \mathrm{~km}$, whereas Western Nayar's length is about $91 \mathrm{~km}$. Eastern Nayar meets Western Nayar at Satpuli. Both of these tributaries join the Ramganga river in the lower Himalayan mountains for around $100 \mathrm{~km}$ further. Remote Sensing data used in this study are google maps of the study area, and Digital Elevation Model (DEM) obtained from
Shuttle Radar Topography Mission (SRTM). QGIS 2.16, open-source software, is used for geospatial analysis.

\subsection{Morphometric analysis}

The formulas used to estimate morphometric parameters viz Stream frequency, Mean bifurcation ratio, Texture ratio, Length of overland flow, Elongation ratio, Circulatory ratio, Form factor and drainage density are presented in Table 1.

Table 1. Description of morphometric parameters used for FAHP prioritization/

\begin{tabular}{|c|c|c|c|}
\hline \begin{tabular}{r|} 
SI. \\
No.
\end{tabular} & Parameter & Definition/Formula & Reference \\
\hline 1 & $\begin{array}{l}\text { Mean } \\
\text { bifurcation } \\
\quad \text { ratio }\end{array}$ & $\begin{array}{l}\qquad R_{b}=\frac{N_{u}}{N_{u+1}} \\
\text { where, } \mathrm{N}_{\mathrm{u}}=\text { complete number } \\
\text { of stream order } \mathrm{u}, \mathrm{N}_{\mathrm{u}+1}= \\
\text { complete number of stream } \\
\text { segment of next higher order }\end{array}$ & $\begin{array}{l}\text { Schumm, } \\
1956\end{array}$ \\
\hline 2 & Texture ratio & $\begin{array}{l}\qquad T=\frac{N_{1}}{P} \\
\text { where, } \mathrm{N}_{1} \text { is complete number } \\
\text { of first order stream and } \mathrm{P}= \\
\text { watershed perimeter }(\mathrm{km})\end{array}$ & $\begin{array}{c}\text { Horton, } \\
1945\end{array}$ \\
\hline 3 & $\begin{array}{c}\text { Stream } \\
\text { frequency }\end{array}$ & $\begin{array}{l}\mathrm{N}_{\mathrm{f}}=\mathrm{It} \text { is the number of streams } \\
\text { per unit area of the watershed }\end{array}$ & $\begin{array}{l}\text { Horton, } \\
1945\end{array}$ \\
\hline 4 & $\begin{array}{l}\text { Length of } \\
\text { overland } \\
\text { flow }\end{array}$ & $\begin{array}{c}L_{o}=0.5 \frac{A}{L_{b}} \\
\text { where, } \mathrm{A}=\text { watershed area } \\
\left(\mathrm{km}^{2}\right) \text { and } \mathrm{L}_{\mathrm{b}} \text { is length of } \\
\text { watershed }\end{array}$ & $\begin{array}{c}\text { Horton, } \\
1945\end{array}$ \\
\hline 5 & $\begin{array}{l}\text { Elongation } \\
\text { ratio }\end{array}$ & $\begin{array}{c}R_{e}=\frac{2}{L_{b}} \sqrt{\frac{A}{\pi}} \\
\text { where, } \mathrm{A}=\text { watershed area } \\
\left(\mathrm{km}^{2}\right) \text { and } \mathrm{L}_{\mathrm{b}} \text { is length of } \\
\text { watershed }\end{array}$ & $\begin{array}{l}\text { Schumm, } \\
1956\end{array}$ \\
\hline 6 & $\begin{array}{l}\text { Circulatory } \\
\text { ratio }\end{array}$ & $\begin{array}{c}\qquad R_{c}=12.57 \frac{A}{P^{2}} \\
\text { where, } \mathrm{P}=\text { watershed perimeter } \\
(\mathrm{km}), \mathrm{A}=\text { watershed area }\left(\mathrm{km}^{2}\right)\end{array}$ & $\begin{array}{l}\text { Miller, } \\
1953\end{array}$ \\
\hline 7 & Form factor & $\begin{array}{c}R_{f}=\frac{A}{L_{b}^{2}} \\
\text { where, } \mathrm{A}=\text { watershed area } \\
\left(\mathrm{km}^{2}\right) \text { and } \mathrm{L}_{\mathrm{b}} \text { is length of } \\
\text { watershed }\end{array}$ & $\begin{array}{c}\text { Horton, } \\
1932\end{array}$ \\
\hline 8 & $\begin{array}{l}\text { Drainage } \\
\text { density }\end{array}$ & $\begin{array}{c}D_{d}=\frac{L_{u}}{A} \\
\text { where, } \mathrm{A}=\text { Basin area }\left(\mathrm{km}^{2}\right), \\
\mathrm{L}_{\mathrm{u}}=\text { complete stream length of } \\
\text { all order }\end{array}$ & $\begin{array}{c}\text { Horton, } \\
1945\end{array}$ \\
\hline 9 & Relief & $\begin{array}{l}\text { vertical distance between the } \\
\text { lowest and highest points of a } \\
\text { watershed }(\mathrm{H})\end{array}$ & $\begin{array}{l}\text { Schumm, } \\
1956\end{array}$ \\
\hline
\end{tabular}

\subsection{Prioritization of sub-watershed using FAHP}

Present study focuses on the use of Fuzzy analytical hierarchical process (FAHP) along with the extent analysis method to prioritize the watershed. Fuzzy AHP is believed to obtain a crisp priority vector from a triangular fuzzy comparison matrix. Linear parameters 
such as bifurcation ratio, texture ratio, have a positive correlation with erodibility, higher value, more soil erodibility. Areal aspects parameter such as circularity ratio, form factor and compactness coefficient have an inverse relationship with erodibility.

The hierarchy process, by the method of extent analysis, each criteria is taken and extent analysis for each criterion, gi; is performed respectively. The $\mathrm{M}$ extent analysis values to each criterion evaluated by full notation

$$
\dot{F}_{g i}^{1}, \dot{F}_{g i}^{2}, \dot{F}_{g i}^{3}, \dot{F}_{g i}^{4}, \ldots \ldots \ldots \ldots \ldots \dot{F}_{g i}^{n}
$$

where, $g_{i}$ is the goal set $(i=1,2,3,4 \ldots . . n)$ and $\dot{F}_{g i}^{j}$ $(j=1,2,3,4, \ldots . m)$ are the members of triangular fuzzy number system (TFNs).

Keeping this in view, the preference values for each morphometric parameter are designated according to the FAHP rating scale, which determines the relative strength of each parameter over other parameters (Saaty 1980). By estimating the consistency ratio (CR), which can be calculated by the following equation, the consistency of judgment can be checked:

$$
C R=\frac{C I}{R I} \times 100
$$

Where the consistency index is a CI, and the random consistency index is a RI. The consistency index is a unit less number, which can be calculated using following equation, depending on the matrix's size (number of parameters).

$$
C I=\frac{\lambda_{\max }-n}{n-1}
$$

Where, $\lambda_{\max }$ is the principal eigen value obtained from priority matrix and $\mathrm{n}$ is the size of comparison matrix.

\section{Result and discussion}

\subsection{Quantification of morphometric parameters}

The morphometric parameters estimated for each of the sub-watersheds are given in Table 2 . These values were acquired as defined in the section on materials and methods and were used in FAHP to construct a pairwise comparison matrix. In the form of a hierarchical tree, nine morphometric assessment indices were used for prioritizing sub-watersheds. Fuzzy analytical hierarchy process (FAHP) was used to evaluate the relative weights of parameters' character traits to prioritize subwatersheds. The Western Nayar watershed is delineated The Western Nayar watershed is delineated into 11 subwatersheds using QGIS 2.6.0 software(Fig.2). The Western Nayar watershed was found to be of fourthorder(Fig. 3). The analysis of the drainage network map reveals that there are 163 first-order streams having a total stream length of $219.72 \mathrm{~km}, 39$ second-order streams with $129.80 \mathrm{~km}$ stream length, 11 third-order streams having $97.05 \mathrm{~km}$ stream length, and 1 fourth-order stream with $48.33 \mathrm{~km}$ stream length.

The perimeter of Western Nayar is estimated as 46.25 $\mathrm{km}$. The sub watershed-wise basin length varies from 6.44 $\mathrm{km}$ to $20.88 \mathrm{~km}$. As per Strahler's approach, the total numbers of streams for watershed are 216 , out of which 163 belongs to first order, 39 are of second-order, 11 are of the third order, 1 is of fourth-order. It revealed that the highest number of streams are found in SW 7 (41), and the lowest number of streams is found in SW 4 (9). The stream frequency of the Western Nayar watershed subwatersheds varies from 0.20 to 0.54 ; the highest stream frequency is observed in SW $4\left(0.54 / \mathrm{km}^{2}\right)$, which indicated that it has the least infiltration capacity and thus highest erosion susceptibility in terms of $\mathrm{N}_{\mathrm{f}}$. Stream frequency is observed the lowest in SW $9\left(0.20 / \mathrm{km}^{2}\right)$, which indicated it possesses the least erosion susceptibility. The mean bifurcation ratio of all the subwatersheds is high, which indicates that all the subwatersheds are structurally complex and have low permeability. Among the SWs, the highest mean bifurcation ratio is observed in SW 2 (5.642), which indicated that it is structurally complex and has low permeability and thus the highest erosion susceptibility in terms of $R_{b m}$. $R_{b m}$ is observed the lowest in SW 4 (2.5), which indicated that it has the least erosion susceptibility. In the Western Nayar watershed, the lowest texture ratio is observed in SW $4(0.14 / \mathrm{km})$, which indicated that it has the highest infiltration capacity among the other SWs or conversely, it has the least susceptibility to erosion if the $\mathrm{T}$ is taken as a criterion for erosion susceptibility.

Table 2. Sub-watershed wise morphometric parameters for Western Nayar watershed.

\begin{tabular}{|c|c|c|c|c|c|c|c|c|c|c|c|c|c|}
\hline Basin & $\mathbf{A}$ & $\mathbf{P}$ & $\mathbf{L}_{\mathbf{u}}$ & $\mathbf{R}_{\mathbf{b m}}$ & $\mathbf{D}_{\mathbf{d}}$ & $\mathbf{~}_{\mathbf{f}}$ & $\mathbf{R}_{\mathbf{c}}$ & $\mathbf{R}_{\mathbf{f}}$ & $\mathbf{C}_{\mathbf{c}}$ & $\mathbf{R}_{\mathbf{e}}$ & $\mathbf{R}$ & $\mathbf{L}_{\mathbf{o}}$ & $\mathbf{T}$ \\
\hline SW1 & 93.55 & 68.98 & 20.88 & 4.62 & 0.65 & 0.28 & 0.25 & 0.21 & 2.01 & 0.52 & 1.75 & 0.77 & 0.30 \\
\hline SW2 & 118.65 & 68.20 & 19.68 & 5.64 & 0.60 & 0.32 & 0.41 & 0.31 & 1.56 & 0.62 & 1.68 & 0.82 & 0.50 \\
\hline SW3 & 50.15 & 42.76 & 9.50 & 4.62 & 0.75 & 0.52 & 0.34 & 0.56 & 1.70 & 0.84 & 1.31 & 0.66 & 0.49 \\
\hline SW4 & 42.37 & 41.53 & 12.97 & 2.50 & 0.64 & 0.54 & 0.31 & 0.25 & 1.80 & 0.57 & 1.58 & 0.77 & 0.14 \\
\hline SW5 & 37.88 & 46.45 & 13.23 & 2.75 & 0.62 & 0.26 & 0.22 & 0.22 & 2.13 & 0.53 & 1.58 & 0.80 & 0.15 \\
\hline SW6 & 30.74 & 32.03 & 6.44 & 2.75 & 0.57 & 0.33 & 0.38 & 0.74 & 1.63 & 0.97 & 1.17 & 0.87 & 0.22 \\
\hline SW7 & 134.62 & 79.99 & 18.34 & 3.87 & 0.77 & 0.30 & 0.26 & 0.40 & 1.94 & 0.71 & 1.70 & 0.64 & 0.38 \\
\hline SW8 & 31.63 & 32.75 & 10.60 & 2.75 & 0.65 & 0.32 & 0.37 & 0.28 & 1.64 & 0.60 & 1.69 & 0.77 & 0.21 \\
\hline SW9 & 60.94 & 51.59 & 17.45 & 3.25 & 0.68 & 0.2 & 0.29 & 0.20 & 1.86 & 0.50 & 0.78 & 0.73 & 0.17 \\
\hline SW10 & 48.51 & 44.38 & 12.42 & 3.25 & 0.56 & 0.25 & 0.31 & 0.31 & 1.80 & 0.63 & 1.24 & 0.89 & 0.20 \\
\hline SW11 & 100.61 & 8.144 & 16.54 & 4.00 & 0.64 & 0.21 & 0.27 & 0.37 & 1.92 & 0.68 & 1.34 & 0.78 & 0.23 \\
\hline
\end{tabular}


The highest texture ratio was observed in SW2 $(0.50 / \mathrm{km})$, which indicated that it has the lowest infiltration capacity and thus highest erosion susceptibility in terms of $\mathrm{T}$. $\mathrm{L}_{\mathrm{o}}$ is less for steeper slopes and high for gentle slopes and thus

directly related to the slope of the channel. In the study area, the highest length of overland flow is observed in SW $10\left(0.89 \mathrm{~km}^{2}\right)$, which indicated that it has the highest potential to erode the land in a single stretch. $\mathrm{L}_{0}$ is observed the lowest in SW7 $\left(0.64 \mathrm{~km}^{2}\right)$, making it the least susceptible to erosion as far as $\mathrm{L}_{\mathrm{o}}$ is concerned.

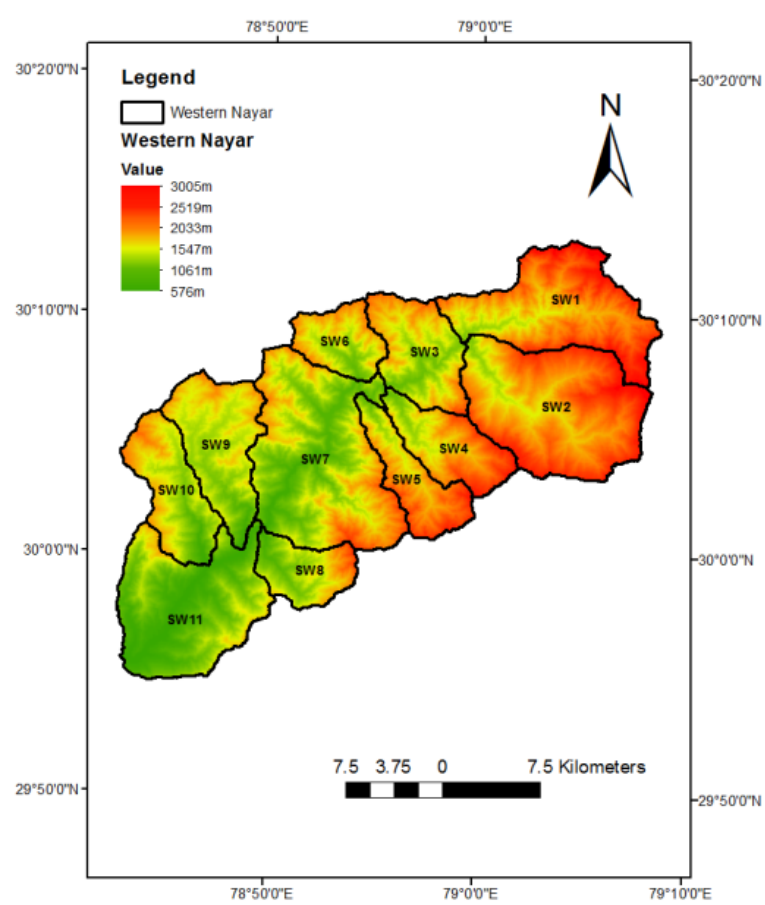

Fig. 2. Digital Elevation Model (DEM) map of western Nayar watershed.

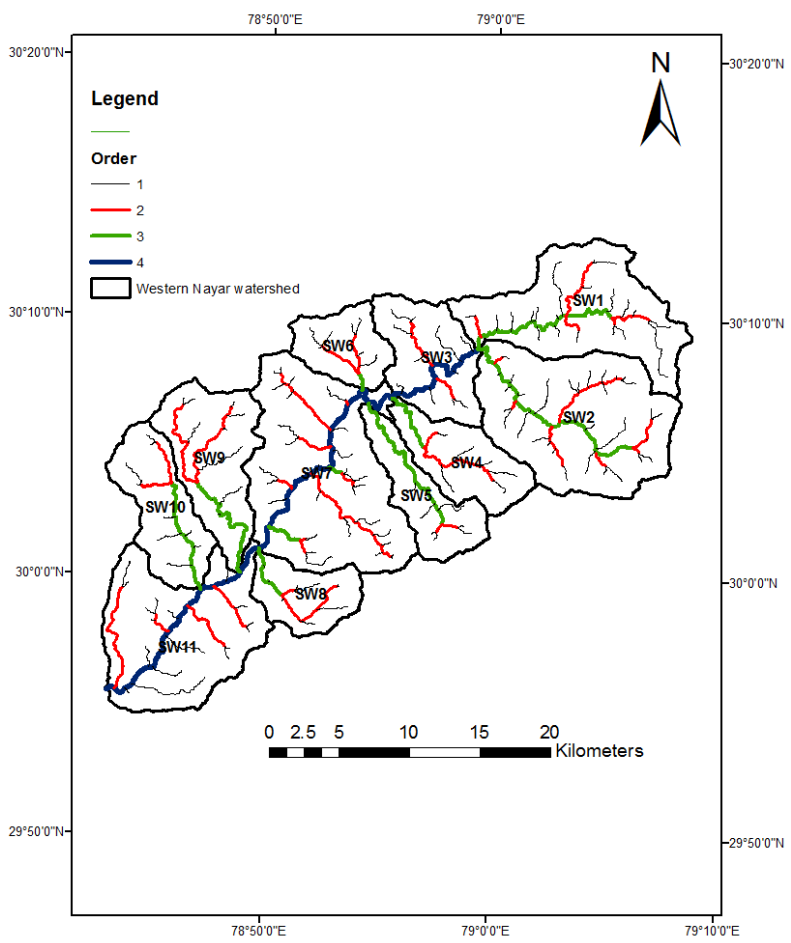

Fig. 3. Drainage network map of Western Nayar watershed.
Areal aspects of the morphological study of watershed include the description of the arrangement of areal elements. The total area of the Western Nayar watershed is estimated as $749.65 \mathrm{~km}^{2}$. The area of SWs varies from $30.74 \mathrm{~km}^{2}$ to $134.62 \mathrm{~km}^{2}$ (Table 2). In the Western Nayar highest elongation ratio is observed in SW6 (0.97), indicating that it has the least susceptibility to erosion in terms of $\mathrm{R}_{\mathrm{e}} . \mathrm{R}_{\mathrm{e}}$ is observed the lowest in SW $9(0.50)$, indicating the highest susceptibility. Among the SWs of the Western Nayar watershed highest Circulatory ratio is observed in SW2 (0.41), indicating low infiltration capacity and more erosion susceptibility in $R_{c}$ terms. $R_{c}$ is observed the lowest in SW 5 (0.22) indicates that it possesses low relief and higher infiltration capacity and resulting in lower susceptibility. The basins with high form factors have peak flows of shorter duration, whereas an elongated watershed with low form factors has a longer duration peak flow. Among the SWs of the Western Nayar watershed, the highest form factor is observed in SW 6 $(0.74)$, indicating that it has peak flows of shorter duration and is least susceptible to erosion in terms of $R_{f}$. $R_{f}$ is observed the lowest in SW 9 (0.20), indicating the highest susceptibility. Among the SWs of the Western Nayar river, the highest Compactness coefficient was observed in SW5 (2.13), indicating it's least susceptible to erosion in terms of $\mathrm{C}_{\mathrm{c}} . \mathrm{C}_{\mathrm{c}}$ is observed the lowest in SW 2 (1.56), indicating the highest susceptibility to erosion.

The relief aspect is a three-dimensional characteristic of a watershed that is expressed in terms of the area, volume, and altitude of watershed landforms. The values of Stream frequency, mean bifurcation ratio, Texture ratio, Length of overland flow, Elongation ratio, Circulatory Ratio, form factor, drainage density and watershed relief are presents in Table 2. Linear parameters such as drainage density, stream frequency, bifurcation ratio, texture of drainage, have a positive correlation with erodibility, higher value, more erodibility. Areal parameters have negative correlation with erodibility, higher value, lower erodibility (Agarwal 1998; Srivastava et al. 2004, Bhattacharya et al 2020).

\subsection{Prioritization of sub-watersheds using fuzzy analytical hierarchy process (FAHP)}

The size of the comparison matrix as presented in Table 3 in Saaty's FAHP is equal to the number of parameters (n) and is in the form of a square matrix. The relative importance between the two factors can be scaled qualitatively between 1 and 9 . Weightage 1 indicates the equal importance to both factors, while 9 indicates that one factor is more important than others. The comparison of each parameter with others is made to complete the comparison matrix of size $(n \times n)$ and the total no. of comparison comes out to be ${ }_{n} C^{2}$. For filling the upper triangle of the matrix, each time two parameters were considered one by one, and considering the relative importance, a value between 1 and 9 is assigned. The lower triangle of the matrix was filled by reciprocal values of upper triangles.

The degree of importance between two factors in the matrix is filled based on field experience. When 
elongation ratio and form factor are used in a pair-wise comparison and it is decided that elongation ratio is important than form factor, a number 2 will be used to fill the element in the upper part of comparison matrix. The elements in the lower part of the matrix can be filled by taking the reciprocal of corresponding elements in the upper matrix. Having the weightage assigned to nine morphometric parameters using FAHP which are 0.238 for Relief (H), 0.184 for the length of overland flow, 0.189 for drainage density, 0.126 for mean bifurcation ratio, 0.080 for stream frequency, 0.054 for texture ratio, 0.049 for elongation ratio, 0.045 for circulatory ratio and 0.030 for form factor as presented in Table 4. The final priority of each sub-watershed is computed using normalized values of morphometric parameters and their respective weightage.

Table 3. Pairwise comparison matrix.

\begin{tabular}{|l|l|l|l|l|l|l|l|l|l|}
\hline & $\mathbf{R}$ & $\mathbf{L}_{\mathbf{o}}$ & $\mathbf{D}_{\mathbf{d}}$ & $\mathbf{R}_{\mathbf{b m}}$ & $\mathbf{N}_{\mathbf{f}}$ & $\mathbf{T}$ & $\mathbf{R}_{\mathbf{e}}$ & $\mathbf{R}_{\mathbf{c}}$ & $\mathbf{R}_{\mathbf{f}}$ \\
\hline $\mathbf{R}$ & 1 & 2 & 2 & 2 & 3.03 & 4 & 4 & 4 & 5 \\
\hline $\mathbf{L}_{\mathbf{o}}$ & 0.5 & 1 & 1 & 2 & 3.03 & 3.03 & 4 & 4 & 5 \\
\hline $\mathbf{D}_{\mathbf{d}}$ & 0.5 & 1 & 1 & 2 & 3.03 & 4 & 4 & 4 & 5 \\
\hline $\mathbf{R}_{\mathbf{b m}}$ & 0.5 & 0.5 & 0.5 & 1 & 2 & 3.03 & 3.03 & 3.03 & 4 \\
\hline $\mathbf{N}_{\mathbf{f}}$ & 0.33 & 0.33 & 0.33 & 0.5 & 1 & 2 & 2 & 2 & 3.03 \\
\hline $\mathbf{T}$ & 0.25 & 0.33 & 0.25 & 0.33 & 0.5 & 1 & 1 & 2 & 2 \\
\hline $\mathbf{R}_{\mathbf{e}}$ & 0.25 & 0.25 & 0.25 & 0.33 & 0.5 & 1 & 1 & 1 & 2 \\
\hline $\mathbf{R}_{\mathbf{c}}$ & 0.25 & 0.25 & 0.25 & 0.33 & 0.5 & 0.5 & 1 & 1 & 2 \\
\hline $\mathbf{R}_{\mathbf{f}}$ & 0.20 & 0.20 & 0.20 & 0.20 & 0.33 & 0.5 & 0.5 & 0.5 & 1 \\
\hline
\end{tabular}

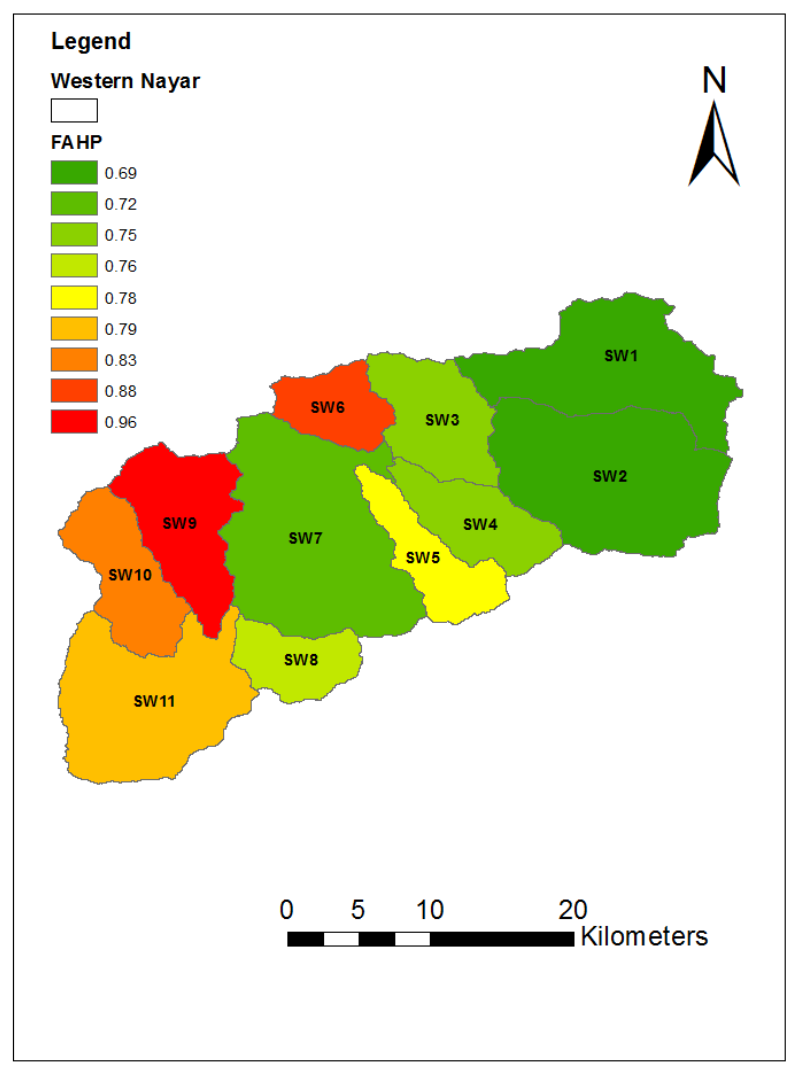

Fig. 4. The prioritized map of sub watersheds of eastern Nayar watershed.

Table 4. Weightage values for nine morphometric parameters.

\begin{tabular}{|l|l|l|l|l|l|l|l|l|l|}
\hline Morphometric parameters & $\mathbf{R}$ & $\mathbf{L}_{\mathbf{o}}$ & $\mathbf{D}_{\mathbf{d}}$ & $\mathbf{R}_{\mathbf{b m}}$ & $\mathbf{N}_{\mathbf{f}}$ & $\mathbf{T}$ & $\mathbf{R}_{\mathbf{e}}$ & $\mathbf{R}_{\mathbf{c}}$ & $\mathbf{R}_{\mathbf{f}}$ \\
\hline Weight $\left(\boldsymbol{X}_{\boldsymbol{i}}\right)$ & 0.238 & 0.184 & 0.189 & 0.126 & 0.080 & 0.054 & 0.049 & 0.045 & 0.030 \\
\hline
\end{tabular}

Table 5. Normalization of morphometric parameters and priority assessment (Western Nayar).

\begin{tabular}{|l|l|l|l|l|l|l|l|l|l|l|l|}
\hline Basin & $\mathbf{R ~ 0 . 2 3 8}$ & $\mathbf{L o ~ 0 . 1 8 4}_{\mathbf{d}} \mathbf{0 . 1 8 9}$ & $\mathbf{R}_{\mathbf{b m}} \mathbf{0 . 1 2 6}$ & $\mathbf{N}_{\mathbf{f}} \mathbf{0 . 0 8 0 6}$ & $\mathbf{T ~ 0 . 0 5 4 8}$ & $\mathbf{R}_{\mathbf{e}} \mathbf{0 . 0 4 9 2}$ & $\mathbf{R}_{\mathbf{c}} \mathbf{0 . 0 4 5 5}$ & $\mathbf{R}_{\mathbf{f}} \mathbf{0 . 0 3 0}$ & Final priority \\
\hline SW1 & 0.668 & 0.844 & 0.861 & 0.539 & 0.714 & 0.466 & 0.53 & 0.609 & 0.28 & 0.690 \\
\hline SW2 & 0.697 & 0.783 & 0.933 & 0.413 & 0.625 & 0.28 & 0.639 & 1 & 0.418 & 0.692 \\
\hline SW3 & 0.893 & 0.984 & 0.746 & 0.539 & 0.389 & 0.285 & 0.865 & 0.829 & 0.756 & 0.752 \\
\hline SW4 & 0.743 & 0.833 & 0.875 & 1 & 0.370 & 1 & 0.587 & 0.756 & 0.337 & 0.751 \\
\hline SW5 & 0.740 & 0.812 & 0.903 & 0.909 & 0.769 & 0.933 & 0.546 & 0.536 & 0.297 & 0.784 \\
\hline SW6 & 1 & 0.747 & 0.982 & 0.909 & 0.606 & 0.636 & 1 & 0.926 & 1 & 0.881 \\
\hline SW7 & 0.690 & 1 & 0.727 & 0.670 & 0.666 & 0.368 & 0.731 & 0.634 & 0.540 & 0.725 \\
\hline SW8 & 0.691 & 0.844 & 0.861 & 0.909 & 0.625 & 0.666 & 0.618 & 0.902 & 0.378 & 0.767 \\
\hline SW9 & 1.51 & 0.878 & 0.823 & 0.8 & 1 & 0.823 & 0.515 & 0.707 & 0.370 & 0.969 \\
\hline SW10 & 0.946 & 0.730 & 1 & 0.8 & 0.8 & 0.7 & 0.649 & 0.756 & 0.418 & 0.831 \\
\hline SW11 & 0.872 & 0.822 & 0.875 & 0.625 & 0.952 & 0.608 & 0.701 & 0.658 & 0.5 & 0.792 \\
\hline
\end{tabular}

The normalization of morphometric parameters for the prioritization of subwatersheds of Western Nayar using FAHP revealed final prioritization ranks (Table 5). The final priority map of the Western Nayar after calculating the final ranks is presented in Fig. 4. The decreasing order of priority of subwatersheds are SW-9(0.969), SW6(0.881), SW-10(0.831), SW-11(0.792), SW-5(0.784), SW-8(0.767), SW-3(0.752), SW-4(0.751), SW-7(0.725), SW-2(0.692), and SW-1(0.690).

\section{Conclusions}

The present study shows the Geographical Information System (GIS) feasibility and Fuzzy Analytical Hieratical Process (FAHP) approaches in morphometric-based subwatershed prioritization Mid-Himalayan watershed. Prioritization centered on FAHP assessment was investigated systematically, which plays a significant role in explaining the issue by integrating environmental resources-causing risk assessment parameters. This 
assortment could be a suitable and effective strategy for developing efficient, sustainable development and management practices, particularly in the conventional watershed prioritization approach. It has been identified in this study that the subwatershed, SW9, and SW6 fall into the top priority category; therefore, these subwatersheds should be given preeminence for conservation by policymakers.

\section{References}

1. C.S. Agarwal, Study of drainage pattern through aerial data in Naugarh area of Varanasi district, U.P., Journal Indian Society of Remote Sensing. 26 (4), 169- 175, (1998)

2. P. Aher, J. Adinarayan, S.D. Gorantiwar, Prioritization of watershed using multi criteria evaluation through fuzzy analytical hierarchy process, Agricultural Engineering International: CIGR Journal, 15(1), 11- 18, (2013)

3. F. Altaf, G. Meraj, S.A. Romshoo, Morphometric Analysis to Infer Hydrological Behaviour of Lidder Watershed, Western Himalaya, India. Geography Journal, (2013)

4. A.K. Batar, R.B. Singh, A. Kumar, Prioritizing watersheds for sustainable development in Swan Catchment area Himachal Pradesh, India, Environmental Geography of South Asia, Advances in Geographical and environment Sciences, 48-66, (2016) (DOI :10.1007/978-4-431-55741-8-3)

5. K. Bera, Prioritization of watershed using Morphometric analysis through Geoinformatics technology: a case study of dungra sub-watershed, West Bengal. International journal of Advances in Remote Sensing and GIS.3:1-8,(2013)

6. S. Biswas, S. Sudhakar, V.R. Desai, Prioritization of sub-watersheds based on Morphometric Analysis of Drainage Basin, District Midnapore, West Bengal. Journal of Indian Society of Remote Sensing 27:155166.(1999)

7. A.D. Bruce, D.F. Arlen, Review of GIS applications in hydrologic modeling, Journal of Water Resources Planning and Management, 119(2), 246-261, (1993)

8. D. Chakrabarthy, D. Dibyendu, S.H. Chandra, Land use indicators of a watershed in arid region Western Rajasthan using Remote sensing and GIS. Journal of the Indian society of Remote sensing.3):115-127, (2001)

9. K.S. Chandniha, M.L. Kansal, Prioritization of subwatersheds based on morphometric analysis using geospatial technique in Piperiya watershed, India, Applied Water Science, 1-10, (2014)

10. R. E. Horton, Erosional development of streams and their drainage basins: a hydrophysical approach to quantitative morphology, Geol Soc Amer Bul,1 56(3), (1945)
11. S.A. Schumm, Evaluation of drainage system and slopes in bed lands at Perth Ambry, New Jersy, Geol Soc Amer Bull,67, 597-646, (1956)

12. V.C. Miller, A quantitative geomorphic study of drainage basin characteristics in the Clinch mountain area, Virginia and Tennesses. Department of Navy, Office of Naval Res., Technical Report 3, Project NR 389-042, Washington DC, (1953)

13. R.E. Horton, Drainage basin characteristics. Transactions American Geophysical Union, 13, 350361, (1932)

14. T.L. Saaty, The analytical hierarchy process. McGraw-Hill, New York, (1980)

15. M. Mekonnen, S.D. Keesstra, J.E. Baartman, L. Stroosnijder, J. Maroulis, Reducing sediment connectivity through man-made and natural sediment sinks in the Minizr Catchment, Northwest Ethiopia, Land Degrad. Dev., 28 (2), 708-717, (2017)

16. A.N. Strahler, Quantitative geomorphology of drainage basins and channel networks. Section 4-II. In: Chow VT (ed) Handbook of applied hydrology. McGraw-Hill, New York, 439-476 (1964)

17. R. K. Bhattacharya, N.C. Chatterjee, K. Das, Subbasin prioritization for assessment of soil erosion susceptibility in Kangsabati, a plateau basin: A comparison between MCDM and SWAT models, Science of The Total Environment,734, (2020)

18. I. Haidara, M. Tahri, M. Maanan, M. Hakdaoui, Efficiency of Fuzzy Analytic Hierarchy Process to detect soil erosion vulnerability, Geoderma,Volume 354, (2019) 